\begin{tabular}{|c|l|}
\hline Title & A re Plumatellid Statoblasts in Freshwater Bryozoans Phy logenetically Informative? \\
\hline Author(s) & Hirose, Masato; Dick, Matthew H.; Mawatari, Shunsuke F. \\
\hline Citation & $\begin{array}{l}\text { Zoological Science, 28(5), 318.326 } \\
\text { https://doi.org/L0.2108/2s.28.318 }\end{array}$ \\
\hline Issue Date & 2011-05 \\
\hline Doc URL & http://hdl.handle.net/2115/56380 \\
\hline Type & article \\
\hline File Information & zsj_28_318.pdf \\
\hline
\end{tabular}

Instructions for use 


\title{
Are Plumatellid Statoblasts in Freshwater Bryozoans Phylogenetically Informative?
}

\author{
Masato Hirose ${ }^{\star}$, Matthew H. Dick and Shunsuke F. Mawatari \\ Department of Natural History Sciences, Faculty of Science, Hokkaido University, \\ N10 W8, Sapporo 060-0810, Japan
}

\begin{abstract}
Morphological characters of statoblasts (including floatoblasts and sessoblasts) in freshwater bryozoans have been important in phylactolaemate systematics and identification in that older phylogenetic hypotheses relied heavily on statoblast morphology. To assess the reliability of statoblast characters in drawing conclusions about phylogeny, we examined the phylogenetic distribution of metric and proportional floatoblast characters, floatoblast symmetry, and floatoblast and sessoblast microsculpture in Plumatellidae, the largest family of phylactolaemates, in the context of molecular phylogenetic reconstructions based on nucleotide sequences of parts of the mitochondrial $12 S$ rRNA, 16S rRNA, and cytochrome $b$ (cytb) genes. Adding cytb sequences to a previous phylogeny based on $12 S$ and $16 S$ increased support only for a node including Plumatella vaihiriae in the $P$. repens clade. Characters of gross floatoblast morphology were generally not phylogenetically informative individually, but collectively discriminated among members of three relatively well-supported clades that were analyzed as pre-defined groups in a discriminant analysis. Two characters of floatoblast microsculpture (reticulation and hypertubercles) were restricted to particular clades; other characters (e.g., villi) were clearly convergent. In nine of 11 cases, fenestral microsculpture was identical or partly correlated between the floatoblast and sessoblast of a species. Overall, our results indicate that statoblast morphology is not highly phylogenetically constrained.
\end{abstract}

Key words: cytochrome $b$, floatoblast, freshwater Bryozoa, microsculpture, molecular phylogeny, morphology, Phylactolaemata, Plumatellidae, sessoblast

\section{INTRODUCTION}

Bryozoans of Class Phylactolaemata can propagate asexually by forming encapsulated dormant bodies called statoblasts. Statoblasts comprise two valves, each composed of an inner capsule containing germinal tissue and food reserves, and an outer periblast comprising a peripheral annulus and a central fenestra. There are two basic types of statoblast: a buoyant type called a floatoblast, and a sessile type called a sessoblast. The annulus of floatoblasts contains chitinous, gas-filled chambers that provide buoyancy (Fig. 1). Sessoblasts are attached by one valve to the substratum; the annulus is reduced and lacks gas-filled chambers.

Statoblast characters have been historically prominent in phylactolaemate identification, classification, and phylogeny reconstruction, for three reasons. First, since statoblasts (Fig. 1) are covered by hard cuticle rather than soft tissue, their characters are more stable than those of the soft colonies, which can be highly variable in morphology, degree of encrustation, and color (Wood and Okamura, 2005). Second, statoblasts are often more persistent in the field than colonies, and the occurrence of a species in an area is often

\footnotetext{
* Corresponding author. Phone: +81-11-706-3524; Fax : +81-11-706-4851; E-mail: m-hirose@mail.sci.hokudai.ac.jp
}

doi:10.2108/zsj.28.318 detected only through statoblasts. Third, the rigid nature of statoblasts makes them more amenable to measurement than are the soft characters of colonies or zooids. Characters such as overall size, the shape of the fenestra and annulus, size ratio of the dorsal to ventral fenestra, ratios of statoblast width, and thickness to statoblast length, and the size of the fenestra relative to statoblast length have been used in systematics (Kraepelin, 1887; Lacourt, 1968; Mukai, 1999; Wood and Okamura, 2005). In addition, in the 1970s, researchers began to use scanning electron microscopy (SEM) to observe the surface microsculpture of statoblasts, and this provided a novel source of systematic characters (Wiebach, 1975; Geimer and Massard, 1986; Wood, 1988, 1998, 2001a, b; Wood and Okamura, 2005; Wood et al., $1998,2006)$, especially for plumatellid species, whose statoblasts are generally similar in gross morphology.

Plumatellidae is the largest family of phylactolaemates, including at least 59 species (Massard and Geimer, 2008), and Plumatella is the most speciose genus within Plumatellidae, with at least 40 species. Morphology-based phylogenetic hypotheses (Toriumi, 1956; Lacourt, 1968; Mukai, 1999; reviewed in Hirose et al., 2008) considered fredericellids to be basal, and plumatellids paraphyletic and near-basal, among phylactolaemates. In the most detailed phylactolaemate phylogeny, Lacourt (1968) used statoblast characters both to delineate species groups within Plumatellidae and to reconstruct relationships among 


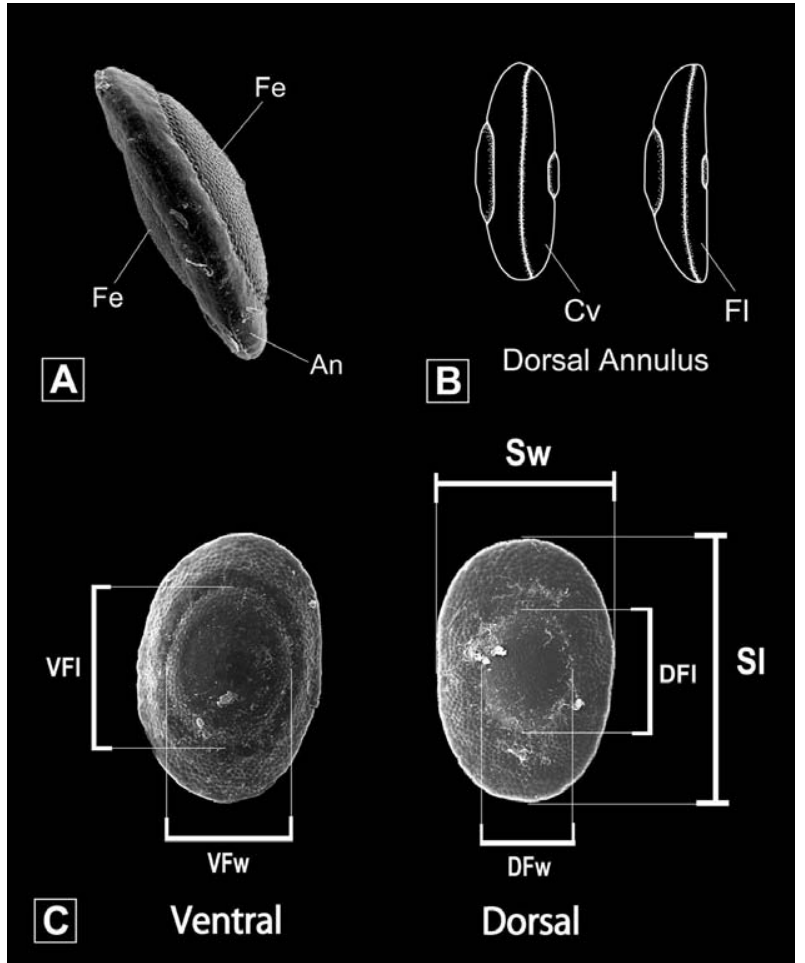

Fig. 1. General floatoblast morphology and characters measured in this study. (A) Side view of a floatoblast. (B) Two types of dorsal annulus resulting in relatively symmetrical (left) or asymmetrical (right) floatoblasts. (C) Ventral and dorsal valves. Abbreviations: An, annulus; $\mathrm{Cv}$, convex dorsal annulus; DFI, dorsal fenestra length; DFw, dorsal fenestra width; Fe, fenestra; FI, flat dorsal annulus; SI, floatoblast length; Sw, floatoblast width; VFI, ventral fenestra length; VFw, ventral fenestra width.

Plumatellidae and other families.

Lacourt's (1968) choice of which statoblast characters were phylogenetically informative was not testable at the time. This is no longer the case, as reconstructions of phylactolaemate phylogeny based on DNA sequence data potentially provide an independent framework within which to evaluate the evolution of statoblast characters. We previously reconstructed the phylogeny of phylactolaemates (Hirose et al., 2008) on the basis of mitochondrial 12S and $16 \mathrm{~S}$ rRNA gene sequences, and this provided a framework for the analysis of plumatellid floatoblast morphology. Because many of the internal nodes lacked support, we attempted to strengthen the analysis by sequencing part of the mitochondrial cytochrome $b$ (cytb) gene for selected species and combining these data with the $12 \mathrm{~S}$ and $16 \mathrm{~S}$ data.

The goals of the present study were to assess whether characters of floatoblast gross morphology, microsculpture, or symmetry are phylogenetically informative in Plumatellidae, and to gain insights into ancestral character states. We focused on floatoblasts because these have a more complex gross morphology than sessoblasts, and because some species of plumatellids lack sessoblasts.

\section{MATERIALS AND METHODS}

\section{Specimen identification and molecular-genetic methods}

We attempted to amplify and sequence a 386-bp cytb fragment from all 14 plumatellid species included in a previous study (Hirose et al., 2008), and were successful for 11 of the species representing three genera (Gelatinella, Hyalinella, Plumatella), and from Internectella bulgarica as an outgroup taxon. We were unable to amplify cytb from Plumatella vorstmani, $P$. sp. 1, or P. sp. 2. Specimens were obtained from Japan, North America, England, and Thailand (Table 1) and were identified to species on the basis of statoblast and colony morphology (when colonies were available). Ancestrulae used for DNA extraction were identified by statoblast morphology prior to germination. Plumatella sp. 1 and sp. 2 from Okinawa are undescribed, morphologically distinct species; these will be formally described elsewhere.

We amplified and sequenced DNA extracted from the tissue of a single colony, single ancestrula, or statoblasts from a single colony to obtain one representative sequence for each species (Table 1). We induced statoblasts to germinate by placing them in distilled water at $25^{\circ} \mathrm{C}$ with light for $3-5$ days, and preserved the resulting ancestrulae in $99 \%$ ethanol. Methods for DNA extraction, PCR amplification, and DNA sequencing were as described in Hirose et al. (2008). For PCR amplification of cytb, we used degenerate primers UCYTB144F (5'-TGA GSN CAR ATG TCN TWY TG-3'), UCYTB272R (5'-GCR AAN AGR AAR TAC CAY TC-3'), UCYTB151F (5'-TGT GGR GCN ACY GTW ATY ACT AA-3'), and UCYTB270R (5'-AAN AGG AAR TAY CAY TCN GGY TG-3') (Merritt et al., 1998) (Table 1) at an annealing temperature of $37^{\circ} \mathrm{C}$. Cytb sequences obtained in this study have been deposited in GenBank under accession numbers AB430866-AB430877.

\section{Phylogenetic analyses}

We retrieved from GenBank $12 S$ and $16 S$ sequences for the same 12 species and individuals (Hirose et al., 2008) from which we amplified cytb (Table 1). We aligned sequences using Clustal W version 1.8 (Thompson et al., 1994; available online at http:// searchlauncher.bcm.tmc.edu/multi-align/multi-align.html) with default parameters, and created two aligned data sets: cytb alone, and cytb concatenated with $12 S$ and $16 S$ sequences. A partition homogeneity test showed congruence among the genes $(P=0.768)$. The 386-bp cytb fragment contained 163 variable and 127 parsimonyinformative sites; the combined data set comprised 1213 positions. We subjected the data to four methods of phylogenetic analysis: maximum parsimony (MP), neighbor joining (NJ), maximum likelihood (ML), and Bayesian analysis (BA). Four gap-rich positions (those having a gap for $>50 \%$ of the taxa included) were discarded before any analyses. The data set analyzed with MP and NJ was 1209 bp long (1213 minus 4 bp), with 354 variable and 196 parsimony-informative sites. Because ML and BA do not handle gaps well, seven additional positions that included gaps were discarded before the analyses, giving a data set 1202 bp long.

Analyses were conducted as described by Hirose et al. (2008), with the following differences specific to this study. The $\mathrm{NJ}$ analysis was conducted with MEGA 4 software (Tamura et al., 2007), and bootstrap values for the MP and NJ trees were obtained from analyses of 1000 pseudoreplicates. Bootstrap values for the ML tree were obtained from 1000 pseudoreplicates analyzed by nearest neighbor interchange (NNI) searches, with the starting topology given by a NJ tree in each case. For the BA, a Markov-chain MonteCarlo (MCMC) search was performed with four chains for $5,000,000$ generations; trees were sampled every 100 generation, and the first 662,000 generations were discarded as burn-in. As before, the best-fit substitution model determined with Modeltest 3.7 (Posada and Crandall, 1998) for ML and with MrModeltest 2.2 (Nylander, 2004) for BA was GTR + I + gamma for both the cytb and combined data sets.

\section{Statoblast morphology}

For 14 plumatellid species (Table 1), we examined 16 floatoblast characters and one sessoblast character (Table 2). Measure- 
Table 1. List of species for which cytb sequences were obtained in this study, localities from which sion numbers. Primer abbreviations: 144F, UCYTB144F; 270R, UCYTB270R; 151F, UCYTB151F; 272R, UCYTB272R.

\begin{tabular}{|c|c|c|c|c|c|}
\hline \multirow{2}{*}{ Species } & \multirow{2}{*}{ Locality } & \multirow{2}{*}{$\begin{array}{l}\text { Tissue } \\
\text { (Primer set) }\end{array}$} & \multicolumn{3}{|c|}{ Accession numbers } \\
\hline & & & $12 S$ & $16 S$ & cytb \\
\hline \multicolumn{6}{|l|}{ Fredericellidae } \\
\hline $\begin{array}{l}\text { Internectella bulgarica } \\
\text { Gruncharova, } 1971\end{array}$ & $\begin{array}{l}\text { Prachin Buri River, } \\
\text { Thailand }\end{array}$ & $\begin{array}{l}\text { colony } \\
(151 \mathrm{~F}-270 \mathrm{R})\end{array}$ & AB365613 & AB365636 & AB430877 \\
\hline \multicolumn{6}{|l|}{ Plumatellidae } \\
\hline $\begin{array}{l}\text { Gelatinella toanensis } \\
\text { (Hozawa \& Toriumi, 1940) }\end{array}$ & $\begin{array}{l}\text { Kai-numa, } \\
\text { Akita, Japan }\end{array}$ & $\begin{array}{l}\text { ancestrula } \\
(144 \mathrm{~F}-270 \mathrm{R})\end{array}$ & AB365607 & AB365630 & AB430875 \\
\hline $\begin{array}{l}\text { Hyalinella punctata } \\
\text { Hancock, } 1850\end{array}$ & $\begin{array}{l}\text { Ohnuma, } \\
\text { Hokkaido, Japan }\end{array}$ & $\begin{array}{l}\text { ancestrula } \\
(144 \mathrm{~F}-270 \mathrm{R})\end{array}$ & AB365608 & AB365631 & AB430874 \\
\hline $\begin{array}{l}\text { Plumatella casmiana } \\
\text { Oka, } 1907\end{array}$ & $\begin{array}{l}\text { Kabuto-numa, } \\
\text { Hokkaido, Japan }\end{array}$ & $\begin{array}{l}\text { ancestrula } \\
(144 \mathrm{~F}-270 \mathrm{R})\end{array}$ & AB365606 & AB365629 & AB430872 \\
\hline $\begin{array}{l}\text { Plumatella emarginata } \\
\text { Allman, } 1844\end{array}$ & $\begin{array}{l}\text { Ohnuma, } \\
\text { Hokkaido, Japan }\end{array}$ & $\begin{array}{l}\text { ancestrula } \\
(144 \mathrm{~F}-270 \mathrm{R})\end{array}$ & AB365603 & AB365626 & AB430870 \\
\hline $\begin{array}{l}\text { Plumatella fungosa } \\
\text { Pallas, } 1768\end{array}$ & $\begin{array}{l}\text { Blenheim Lake, } \\
\text { Oxfordshire, England }\end{array}$ & $\begin{array}{l}\text { statoblast } \\
(151 \mathrm{~F}-272 \mathrm{R})\end{array}$ & AB365601 & AB365624 & AB430868 \\
\hline $\begin{array}{l}\text { Plumatella minuta } \\
\text { (Toriumi, 1941) }\end{array}$ & $\begin{array}{l}\text { Hyotaro-ike, } \\
\text { Ibaraki, Japan }\end{array}$ & $\begin{array}{l}\text { colony } \\
(144 \mathrm{~F}-270 \mathrm{R})\end{array}$ & AB365612 & AB365635 & AB430876 \\
\hline $\begin{array}{l}\text { Plumatella mukaii } \\
\text { Wood, } 2001\end{array}$ & $\begin{array}{l}\text { Suge-numa, } \\
\text { Gunma, Japan }\end{array}$ & $\begin{array}{l}\text { colony } \\
(144 \mathrm{~F}-270 \mathrm{R})\end{array}$ & AB365604 & AB365627 & AB430873 \\
\hline $\begin{array}{l}\text { Plumatella repens } \\
\text { (Linnaeus, 1758) }\end{array}$ & $\begin{array}{l}\text { Ohnuma, } \\
\text { Hokkaido, Japan }\end{array}$ & $\begin{array}{l}\text { ancestrula } \\
(144 \mathrm{~F}-270 \mathrm{R})\end{array}$ & AB365599 & AB365622 & AB430866 \\
\hline $\begin{array}{l}\text { Plumatella reticulata } \\
\text { Wood, } 1988\end{array}$ & $\begin{array}{l}\text { Huffman Lake, } \\
\text { Ohio, USA }\end{array}$ & $\begin{array}{l}\text { statoblast } \\
(144 \mathrm{~F}-270 \mathrm{R})\end{array}$ & AB365605 & AB365628 & AB430871 \\
\hline $\begin{array}{l}\text { Plumatella rugosa } \\
\text { (Wood, Wood, Geimer } \\
\text { \& Massard, 1998) }\end{array}$ & $\begin{array}{l}\text { Yoshino Park, } \\
\text { Ibaraki, Japan }\end{array}$ & $\begin{array}{l}\text { ancestrula } \\
(151 \mathrm{~F}-270 \mathrm{R})\end{array}$ & AB365600 & AB365623 & AB430867 \\
\hline $\begin{array}{c}\text { Plumatella vaihiriae } \\
\text { (Hastings, 1929) }\end{array}$ & $\begin{array}{l}\text { Wastewater plant, } \\
\text { Phoenix, Arizona, USA }\end{array}$ & $\begin{array}{l}\text { colony } \\
(151 \mathrm{~F}-270 \mathrm{R})\end{array}$ & AB365602 & AB365625 & AB430869 \\
\hline $\begin{array}{l}\text { Plumatella vorstmani } \\
\text { Toriumi, } 1952\end{array}$ & $\begin{array}{l}\text { Pond in Higashisendai, } \\
\text { Miyagi, Japan }\end{array}$ & $\begin{array}{l}\text { ancestrula } \\
(-)\end{array}$ & AB365611 & AB365634 & - \\
\hline Plumatella sp. 1 & $\begin{array}{l}\text { Fukuji Dam, } \\
\text { Okinawa, Japan }\end{array}$ & $\begin{array}{l}\text { ancestrula } \\
(-)\end{array}$ & AB365610 & AB365633 & - \\
\hline Plumatella sp. 2 & $\begin{array}{l}\text { Ryutan-ike, } \\
\text { Okinawa, Japan }\end{array}$ & $\begin{array}{l}\text { ancestrula } \\
(-)\end{array}$ & AB365609 & AB365632 & - \\
\hline
\end{tabular}
specimens were obtained, tissue used for DNA extraction, cytb primer set used, and GenBank acces-

species sampled. For six of the species, for example, the sample came from the population of free-floating floatoblasts at a locality; in two of these cases, no corresponding colonies were detected, and in four cases colonies lacking floatoblasts were also detected. In five cases, floatoblasts came from a single colony.

Measurements were taken in dorsal or ventral view, and included the length and width of the floatoblast $(\mathrm{SI}, \mathrm{Sw})$ and of the fenestrae on the ventral and dorsal valves (VFI, VFw, DFI, DFw), as defined in Fig. 1. We calculated areas (Sa, VFa, DFa) as normal ellipses. As a measure of the degree of ellipticality, we calculated the length/width ratio for the floatoblast $(\mathrm{SI} / \mathrm{Sw})$, ventral fenestra (VFI/VFw), and dorsal fenestra (DFI/DFw), using the ratio values from individual statoblasts to calculate mean ratio values and their standard deviations. In similar fashion, we calculated the length, width, and area ratios of the ventral to the dorsal fenestra (VFI/DFI, VFw/ DFw, VFa/DFa).

We determined the states (Table 2) of three qualitative floatoblast characters, as follows: 1) Symmetry (DAn), two states: $\mathrm{Cv}$, relatively symmetrical, with the dorsal annulus convex; FI, relatively asymmetrical, with the dorsal annulus flat or nearly so. 2) Microsculpture on the fenestra (FMs), five states: $\mathrm{Tb}$, tubercles; $\mathrm{Ht}$, hypertubercles (a hypertubercle is an additional small tubercle atop a primary tubercule; Wood et al., 2006); $\mathrm{Tr}$, tubercles with reticulation; Rt, reticulation; Tv, tubercles with villi. 3) Microsculpture on the annulus (AMs), five states: Sm, smooth; Pm, pavement; Pv, pavement with villi; $\mathrm{Tr}$, tubercles with reticulation; Rt, reticulation. We also determined the states of microsculpture on the capsule of sessoblast (Ses), four states, as same as microsculpture on floatoblast. We detected no differences in the pattern of sculp-

ments were made from wet floatoblasts with an ocular micrometer, or taken from SEM images with ImageJ $1.37 \mathrm{v}$ software (Image Processing and Analysis in Java, Wayne Rasband, National Institutes of Health, USA; http://rsb.info.nih.gov/ij/). For each species, we measured 10 floatoblasts, in each case collected from a single locality on a single date. The source of floatoblasts, and thus their representation of the population as a whole, varied among the turing between the dorsal and ventral valves of floatoblasts.

For light microscopic imaging of floatoblast gross morphology, the dorsal and ventral valves of single floatoblasts were separated by $\mathrm{KOH}$ treatment (Wood, 1989) and photographed through a light microscope, with all floatoblasts photographed at the same magnification. The outlines of valves and fenestrae were traced with Adobe Illustrator software, and the dorsal and ventral tracings for 
Table 2. Abbreviations for morphological characters of statoblasts. Asterisks indicate characters used in the discriminant analysis.

\begin{tabular}{ll}
\hline Abbreviation & Character \\
\hline $\mathrm{SI}$ & floatoblast length* \\
$\mathrm{Sw}$ & floatoblast width* \\
floatoblast area \\
$\mathrm{Sa}$ & floatoblast length/width ratio* \\
$\mathrm{SI} / \mathrm{Sw}$ & ventral fenestra length* \\
VFI & ventral fenestra width* \\
VFw & ventral fenestra length/width ratio* \\
VFI/VFw & dorsal fenestra length* \\
DFI & dorsal fenestra width* \\
DFw & dorsal fenestra length/width ratio* \\
DFI/DFw & V/D fenestra length ratio* \\
VFI/DFI & V/D fenestra width ratio* \\
VFw/DFw & V/D fenestra area ratio \\
VFa/DFa & dorsal annulus shape (convex or flat) \\
DAn & microsculpture on fenestra \\
FMs & microsculpture on annulus \\
AMs & microsculpture on sessoblast capsule \\
Ses &
\end{tabular}

each species were compiled, preserving the relative sizes of the floatoblasts.

For SEM observation, wet statoblasts were dehydrated with hexamethyldisilazane (HMDS), coated with Pd-Pt in a Hitachi E1030 sputter-coater, and observed with a Hitachi S-2250N scanning electron microscope at $15 \mathrm{kV}$ accelerating voltage. Images were captured electronically. To verify that the process of drying and coating statoblasts for SEM did not cause shrinkage, and thus did not affect measurements, we compared length and width measurements between six dried floatoblasts coated for SEM and six wet statoblasts (LM) from a single population each of $P$. casmiana and $G$. toanensis; measurements were taken from light micrographs. There was no significant difference $(P<0.05$; t-test) in floatoblast length or width measurements between the two treatments for either species (For $P$. casmiana, mean SILM $=353 \mu \mathrm{m}$, SISEM $=$ $353 \mu \mathrm{m}, P=0.94 ;$ SWLM $=219 \mu \mathrm{m}$, SWSEM $=227 \mu \mathrm{m}, P=0.14$. For G. toanensis, $\mathrm{SILM}_{\mathrm{LM}}=517 \mu \mathrm{m}, \mathrm{SI}_{\mathrm{SEM}}=535 \mu \mathrm{m}, P=0.14$; $\mathrm{SW}_{\mathrm{LM}}=$ $\left.330 \mu \mathrm{m}, \mathrm{SW}_{\mathrm{SEM}}=344 \mu \mathrm{m}, P=0.41\right)$.

\section{Discriminant analysis}

To test whether gross morphological floatoblast characters in combination might discriminate between clades, we conducted a linear discriminant analysis using R 2.8.0 software (R Development Core Team, 2008). We pre-assigned three groups ('Group' column

Table 3. Values for floatoblast characters and one sessoblast character for 14 plumatellid species. In the SI, Sw, VFI, VFw, DFI, and DFw columns are average values (in micrometers) for 10 statoblasts; in the Sa column is floatoblast area in $\mathrm{mm}^{2} \times 100$. In the SI/Sw, VFI/VFw, DFI/ DFw, VFI/DFI, VFw/DFw, and VFa/DFa columns are average ratio values. Standard deviations for measurements and ratios used in the discriminant analysis are in parentheses. The DAn column indicates floatoblast symmetry. The FMs and AMs columns indicate the microsculpture on the floatoblast fenestra and annulus, respectively (see Methods for abbreviations of character states). The Ses column indicates the microsculpture on the capsule of the sessoblast; (-) indicates that a species lacks a sessoblast. The Group column indicates the pre-assigned groups defined for the discriminant analysis. Character abbreviations are defined in Table 2.

\begin{tabular}{|c|c|c|c|c|c|c|c|c|c|c|c|c|c|c|c|c|c|c|}
\hline \multirow{2}{*}{ SPECIES } & \multicolumn{18}{|c|}{ CHARACTERS } \\
\hline & SI & Sw & $\mathrm{Sa}$ & $\mathrm{SI} / \mathrm{Sw}$ & VFI & VFw & VFI/VFw & DFI & DFw & DFI/DFw & $\mathrm{VFI} / \mathrm{DFI}$ & VFw/DFw & VFa/DFa & DAn & FMs & AMs & Ses & Group \\
\hline \multirow[t]{2}{*}{ P. fungosa } & 367 & 294 & 8.5 & 1.3 & 225 & 206 & 1.1 & 157 & 155 & 1.0 & 1.4 & 1.3 & 1.9 & $\mathrm{Cv}$ & $\mathrm{Tr}$ & $\mathrm{Tr}$ & $\mathrm{Tb}$ & 1 \\
\hline & (18.87) & (12.46) & & $(0.09)$ & (24.13) & (9.95) & $(0.10)$ & $(9.80)$ & (7.89) & $(0.03)$ & $(0.17)$ & $(0.09)$ & & & & & & \\
\hline \multirow[t]{2}{*}{ P. repens } & 353 & 258 & 7.1 & 1.4 & 228 & 198 & 1.2 & 180 & 160 & 1.1 & 1.3 & 1.2 & 1.6 & $\mathrm{Cv}$ & $\operatorname{Tr}$ & Sm & $\mathrm{Tb}$ & 1 \\
\hline & $(7.50)$ & (16.00) & & $(0.06)$ & (13.46) & $(7.50)$ & $(0.08)$ & (26.93) & (16.58) & $(0.12)$ & $(0.21)$ & $(0.11)$ & & & & & & \\
\hline \multirow[t]{2}{*}{ P. rugosa } & 398 & 313 & 9.8 & 1.3 & 248 & 208 & 1.2 & 202 & 170 & 1.2 & 1.2 & 1.2 & 1.5 & $\mathrm{Cv}$ & $\operatorname{Tr}$ & Rt & $\mathrm{Tb}$ & 1 \\
\hline & $(7.50)$ & (20.16) & & (0.08) & (23.58) & (16.00) & $(0.08)$ & (17.50) & (21.79) & $(0.13)$ & $(0.05)$ & $(0.15)$ & & & & & & \\
\hline \multirow[t]{2}{*}{ P. vaihiriae } & 339 & 208 & 5.5 & 1.6 & 236 & 183 & 1.3 & 198 & 137 & 1.4 & 1.2 & 1.3 & 1.6 & $\mathrm{Cv}$ & Rt & Rt & Rt & 1 \\
\hline & $(5.25)$ & (3.14) & & $(0.03)$ & $(3.80)$ & $(2.24)$ & $(0.02)$ & (2.28) & (1.62) & $(0.02)$ & $(0.03)$ & $(0.03)$ & & & & & & \\
\hline \multirow[t]{2}{*}{ P. casmiana } & 354 & 227 & 6.3 & 1.6 & 215 & 160 & 1.4 & 202 & 128 & 1.6 & 1.1 & 1.3 & 1.3 & Cv & $\mathrm{Tb}$ & Pm & $\mathrm{Sm}$ & - \\
\hline & $(9.09)$ & (7.41) & & $(0.06)$ & $(8.17)$ & $(8.67)$ & $(0.11)$ & (18.35) & $(6.90)$ & $(0.14)$ & $(0.09)$ & $(0.07)$ & & & & & & \\
\hline \multirow[t]{2}{*}{ P. mukaii } & 382 & 218 & 6.5 & 1.8 & 196 & 162 & 1.2 & 125 & 91 & 1.4 & 1.6 & 1.8 & 2.9 & $\mathrm{FI}$ & Tv & $\mathrm{Pv}$ & Tv & 2 \\
\hline & (19.26) & (14.35) & & $(0.12)$ & $(7.89)$ & (11.22) & $(0.10)$ & (18.44) & (8.79) & $(0.18)$ & $(0.22)$ & $(0.23)$ & & & & & & \\
\hline \multirow[t]{2}{*}{ P. reticulata } & 388 & 230 & 7.0 & 1.7 & 191 & 180 & 1.1 & 101 & 84 & 1.2 & 1.9 & 2.2 & 4.1 & $\mathrm{Cv}$ & $\mathrm{Tb}$ & $\mathrm{Pm}$ & Rt & 2 \\
\hline & $(37.50)$ & (21.79) & & $(0.18)$ & (17.44) & (18.71) & $(0.07)$ & (11.58) & (11.36) & $(0.23)$ & $(0.23)$ & $(0.25)$ & & & & & & \\
\hline \multirow[t]{2}{*}{$P$. emarginata } & 390 & 205 & 6.3 & 1.9 & 175 & 155 & 1.1 & 105 & 70 & 1.6 & 1.7 & 2.3 & 3.9 & $\mathrm{FI}$ & $\mathrm{Tb}$ & $\mathrm{Pm}$ & $\mathrm{Tb}$ & - \\
\hline & $(30.00)$ & (15.00) & & $(0.12)$ & (22.36) & (10.00) & $(0.12)$ & (10.00) & (15.00) & $(0.41)$ & $(0.19)$ & $(0.47)$ & & & & & & \\
\hline \multirow[t]{2}{*}{ H. punctata } & 455 & 312 & 11.2 & 1.5 & 254 & 204 & 1.2 & 214 & 165 & 1.3 & 1.2 & 1.2 & 1.5 & $\mathrm{FI}$ & $\mathrm{Tb}$ & $\mathrm{Pm}$ & - & - \\
\hline & $(22.44)$ & (24.94) & & $(0.10)$ & (16.69) & (14.58) & $(0.08)$ & (16.64) & (19.27) & $(0.14)$ & $(0.10)$ & $(0.08)$ & & & & & & \\
\hline \multirow[t]{2}{*}{ G. toanensis } & 530 & 344 & 14.4 & 1.5 & 315 & 274 & 1.2 & 234 & 179 & 1.3 & 1.3 & 1.5 & 2.1 & $\mathrm{FI}$ & Tv & $\mathrm{Pv}$ & $\mathrm{Tb}$ & - \\
\hline & (21.53) & (26.87) & & $(0.08)$ & $(9.82)$ & (20.91) & $(0.10)$ & (14.68) & (16.37) & $(0.21)$ & $(0.07)$ & $(0.09)$ & & & & & & \\
\hline \multirow[t]{2}{*}{ P. minuta } & 285 & 221 & 5.0 & 1.3 & 217 & 170 & 1.3 & 184 & 152 & 1.2 & 1.2 & 1.1 & 1.3 & $\mathrm{Cv}$ & $\mathrm{Ht}$ & $\mathrm{Pm}$ & - & 3 \\
\hline & $(15.45)$ & (10.70) & & $(0.05)$ & (11.91) & $(8.70)$ & $(0.05)$ & (14.08) & $(7.84)$ & $(0.05)$ & $(0.09)$ & $(0.07)$ & & & & & & \\
\hline \multirow[t]{2}{*}{ P. vorstmani } & 328 & 207 & 5.5 & 1.6 & 170 & 146 & 1.2 & 146 & 122 & 1.2 & 1.2 & 1.2 & 1.4 & $\mathrm{Cv}$ & $\mathrm{Ht}$ & Pm & Tb & 3 \\
\hline & (21.39) & $(9.82)$ & & $(0.16)$ & (10.12) & (7.39) & $(0.07)$ & $(9.27)$ & (9.01) & $(0.04)$ & $(0.06)$ & $(0.06)$ & & & & & & \\
\hline \multirow[t]{2}{*}{ Plumatella sp. 2} & 328 & 227 & 5.9 & 1.4 & 199 & 175 & 1.1 & 197 & 156 & 1.3 & 1.0 & 1.1 & 1.1 & Cv & $\mathrm{Ht}$ & $\mathrm{Pm}$ & - & 3 \\
\hline & (10.62) & (10.90) & & $(0.07)$ & (11.89) & $(7.60)$ & $(0.07)$ & (6.67) & (5.04) & $(0.02)$ & (0.05) & $(0.04)$ & & & & & & \\
\hline Plumatella sp. 1 & $\begin{array}{c}371 \\
(18.25)\end{array}$ & $\begin{array}{c}230 \\
(20.41)\end{array}$ & & $\begin{array}{c}1.7 \\
(0.11)\end{array}$ & $\begin{array}{c}246 \\
(3.44)\end{array}$ & $\begin{array}{c}194 \\
(2.10)\end{array}$ & $\begin{array}{c}1.3 \\
(0.01)\end{array}$ & $\begin{array}{c}192 \\
(7.52)\end{array}$ & $\begin{array}{c}154 \\
(4.92)\end{array}$ & $\begin{array}{c}1.2 \\
(0.03)\end{array}$ & $\begin{array}{c}1.3 \\
(0.04)\end{array}$ & $\begin{array}{c}1.3 \\
(0.04)\end{array}$ & 1.6 & $\mathrm{Fl}$ & $\mathrm{Ht}$ & $\mathrm{Pm}$ & $\mathrm{Tb}$ & 3 \\
\hline
\end{tabular}


in Table 3) based on the tree shown in Fig. 2: Group 1 comprised the $P$. repens clade $(P$. repens, $P$. fungosa, $P$. rugosa, and $P$. vaihiriae); Group 2 comprised $P$. mukaii and $P$. reticulata; and Group 3 comprised Clade 1 (P. minuta, P. vorstmani, Plumatella sp. 1 , and Plumatella sp. 2). These were all well-supported monophyletic groups in Fig. 2 and/or Fig. 3. We performed the analyses using six measurements and five character ratios (indicated by asterisks in Table 2) determined for 100 floatoblasts (10 for each of the 10

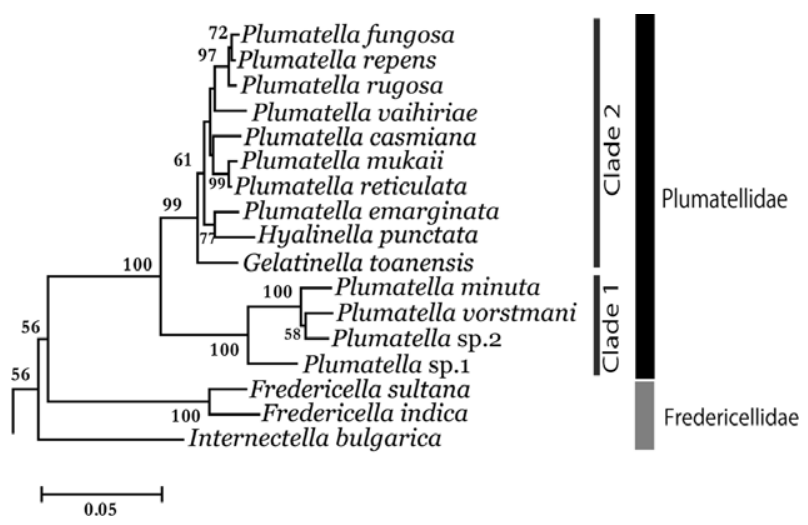

Fig. 2. Neighbor-joining (NJ) tree based on a combined $(12 \mathrm{~S}+$ 16S) data set, adapted from Hirose et al. (2008). The scale bar indicates branch length in substitutions per site. Numbers near nodes are bootstrap values greater than $50 \%$, based on analysis of 10,000 pseudoreplicates.
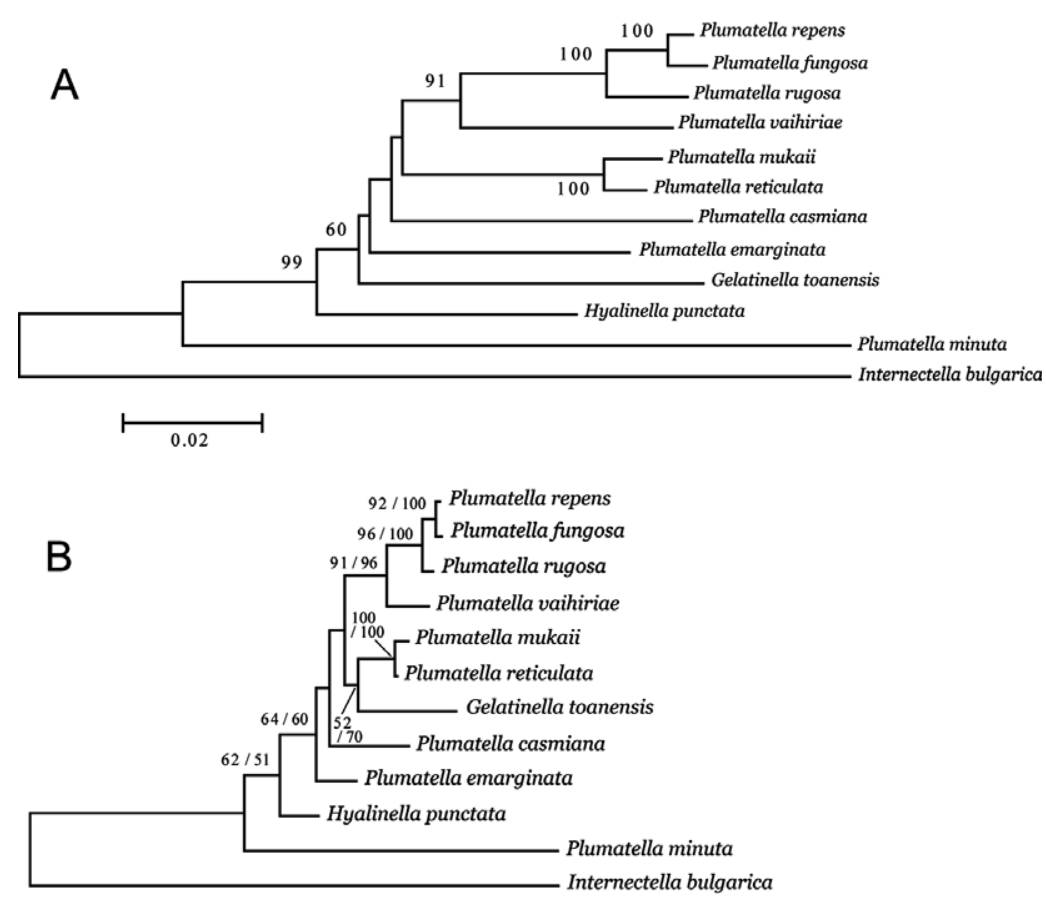

${ }_{0.02}^{H}$

Fig. 3. (A) Neighbor-joining (NJ) tree based on the combined (12S + 16S + cytb) data set; numbers near nodes are bootstrap values based on analysis of 1000 pseudoreplicates. (B) Bayesian (BA) tree based on the combined $(12 \mathrm{~S}+16 \mathrm{~S}+$ cytb) data set, with numbers near nodes indicating the bootstrap value from a maximum likelihood (ML) analysis of the same data set, based on 1000 pseudoreplicates, followed by the Bayesian posterior probability (only values greater than $50 \%$ are shown). species in the analysis). We did not include characters of microscuIpture or symmetry, so as to avoid bias in numerically coding these characters.

\section{RESULTS}

Phylogenetic analysis

The trees produced by analyzing the cytb data set alone and the combined data set $(12 S+16 S+c y t b)$ by four methods (MP, NJ, ML, and BA) were nearly all identical in topology; only the $\mathrm{NJ}$ tree from the combined data set gave a topology different from the others. Here we show the $\mathrm{NJ}$ and BA trees based on the combined data set (Fig. 3). All trees showed the following relationships, with high nodal support: (1) Plumatella minuta, the only representative of Clade 1 (Fig. 2) included in the analysis, forms the sister taxon to other plumatellids. (2) Plumatella is paraphyletic, including some but not all of the descendants of the most recent common ancestor of Plumatella species (i.e., also including species of Gelatinella and Hyalinella). (3) Plumatella repens, $P$. fungosa, $P$. rugosa, and $P$. vaihiriae comprise a monophyletic group, hereafter called the ' $P$. repens clade'. (4) Plumatella mukaii and $P$. reticulata comprise a monophyletic group.

The NJ tree differed from other trees only in the placement of $G$. toanensis; removal of this species from all trees resulted in an identical topology. Backbone nodes between the node uniting the $P$. repens clade and the node that splits off $H$. punctata from other plumatellids were weakly supported in the trees.

The addition of the cytb fragment to the $12 S+16 S$ data set only marginally increased the robustness of the phylogeny (Fig. 3) over that previously produced from the $12 S+16 S$ data set alone (Fig. 2). In Fig. 3, there is increased support for $P$. vaihiriae as the sister group to the $P$. repens $-P$. fungosa $-P$. rugosa clade. In the new analysis including $c y t b$, Plumatella casmiana shifted from a position as the sister group to $P$. mukaii $+P$. reticulata to a more basal position, and the sister-group relationship of $P$. emarginata with $H$. punctata disintegrated; however, these changes in position lacked support.

\section{Floatoblast gross morphology}

Summaries of gross floatoblast characters among the plumatellids studied are given in Table 3 and Fig. 4. No phylogenetic pattern was evident in the shapes of floatoblasts or fenestrae (Table 3). For example, the floatoblast length/width ratio (SI/Sw) varied continuously from 1.3 to 1.9; species in Clade 1 ranged from 1.3 to 1.7 and species in Clade 2 similarly ranged from 1.3 to 1.9 . The length/ width ratio of the ventral fenestra (VFI/VFw) varied continuously from 1.1 to 1.4 , and that of the dorsal fenestra (DFl/DFw) also varied almost continuously from 1.0 to 1.6 .

The relative sizes of the dorsal and ventral fenestrae differed among plumatellids, though again no strong phylogenetic pattern was evi- 


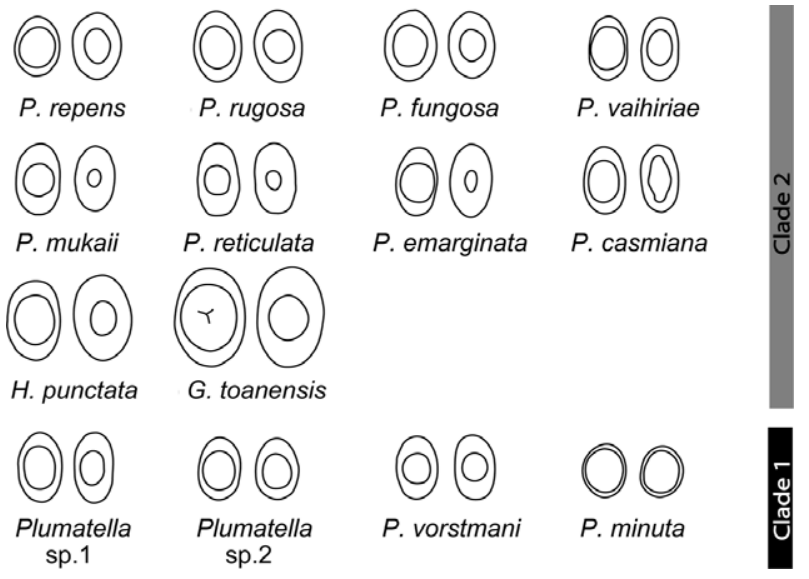

Fig. 4. Schematic illustration of general floatoblast morphology, showing the ventral (left) and dorsal (right) valves of the 14 plumatellid species included in this study, all to the same scale. The bars at the right indicate the two major plumatellid clades delineated in molecular phylogenetic analyses.

dent (Table 3; Fig. 4). There was no diagnostic difference in $\mathrm{VFa} / \mathrm{DFa}$ between plumatellid Clades 1 and 2; the range in values for Clade 1 was 1.1-1.6, and five taxa in Clade 2 fell in this range. The ratio of the ventral to dorsal fenestral areas (VFa/DFa) varied almost continuously from 1.1 to 2.1 among most species, while $P$. mukaii, $P$. emarginata, and $P$. reticulata had larger ratios ( $\geq 2.9$; Table 3 ). Plumatella reticulata and $P$. mukaii comprised a well-supported clade, whereas Plumatella emarginata grouped with $H$. punctata $(\mathrm{VFa} / \mathrm{DFa}=1.5)$ (Fig. 2) or was positioned between $P$. casmiana $(\mathrm{VFa} / \mathrm{DFa}=1.3)$ and $\mathrm{G}$. toanensis $(\mathrm{VFa} / \mathrm{DFa}=$ 2.1) (Fig. 3A) or $H$. punctata (Fig. 3B). At face value, the trees indicate that a large difference in size between the dorsal and ventral fenestrae is synapomorphic for the reticulata-mukaii clade, but autapomorphic for $P$. emarginata; however, support for nodes separating $P$. emarginata from the reticulata-mukaii clade was low $(\leq 60 \%)$, and this character may have phylogenetic significance.

Floatoblasts ( $\mathrm{Sa}$, Table 3 ) varied almost continuously in size $\left(\mathrm{Sa}=0.055-0.112 \mathrm{~mm}^{2}\right)$ among most species in Clade 2 (Fig. 2), although that of $G$. toanensis was exceptionally large $\left(0.144 \mathrm{~mm}^{2}\right)$; there was large variation even within the $P$. repens clade; and sizes overlapped between Clades 1 and 2 . Floatoblast size is thus generally not phylogenetically informative. Some phylogenetic patterns were evident, however: members of the fungosa-repens-rugosa clade had the largest floatoblasts among the species of Plumatella examined, and members of the Plumatella sp. $2-P$. minuta $-P$. vorstmani clade had small floatoblasts (among other plumatellid species, only $P$. vaihiriae fell within the size range of these three species).

Gelatinella toanensis, $H$. punctata, $P$. emarginata, $P$. mukaii, and $P$. sp. 1 all had floatoblasts markedly asymmetrical in side view (DAn column, Table 3); these species did not comprise a monophyletic group, and included representatives of both Clade 1 and Clade 2. Conversely, floatoblast symmetry differed between sister taxa $P$. mukaii and $P$. reticulata. Floatoblast symmetry is thus not phylogenetically informative.

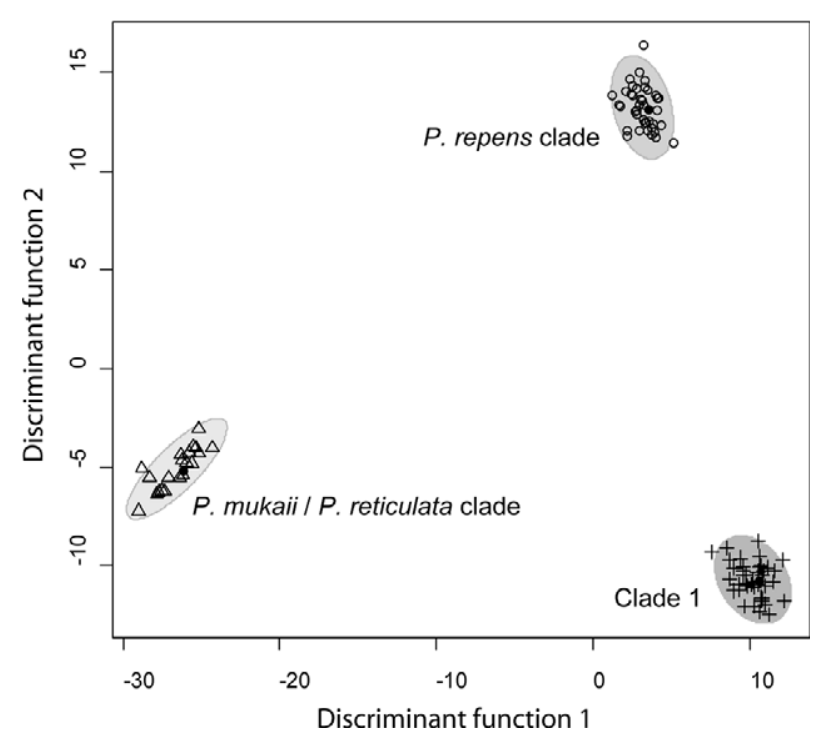

Fig. 5. Canonical plot based on a discriminant analysis of six metric and five ratio characters for 107 floatoblasts from individuals of 14 plumatellid species. The species comprising Groups 1-3 are indicated in Table 3. $\bigcirc$, individuals of Group-1 species ( $P$. repens clade); $\Delta$, individuals of Group-2 species (P. mukaii/P. reticulata clade); +, individuals of Group-3 species (Clade 1). Shaded ellipses indicate the $95 \%$ confidence limits for each group centroid.

Table 4. Results of the discriminant analysis of pre-assigned Groups 1-3 (Table 3), based on 11 floatoblast characters.

\begin{tabular}{ccc}
\hline $\begin{array}{c}\text { Discriminant } \\
\text { function }\end{array}$ & Eigenvalue & $\begin{array}{c}\text { Characters with the three } \\
\text { largest standard coefficients }\end{array}$ \\
\hline 1 & 192.3 & DFI, DFI/DFw, VFw \\
2 & 124.3 & VFw, DFI, SI \\
\hline
\end{tabular}

\section{Discriminant analysis}

A canonical plot (Fig. 5) from the discriminant analysis shows the centroids of pre-assigned Groups 1-3 well separated. In the first discriminant function, dorsal fenestra length (DFI), the dorsal fenestra length/width ratio (DFI/DFw), and ventral fenestra width (VFw) were the main predictors (Table 4). The three groups were completely separated along both axes, with no overlap among points or centroids.

\section{Floatoblast microsculpture}

In assigning character states for microsculpture (Fig. 6), we defined intermediate stages within essentially continuous variation reflecting the relative degree of development of tubercles and reticulation, ranging from 'Sm' (evidence of tuberculation almost absent) (Fig. 6A); to 'Pm' (rudimentary tuberculation giving a cobbled pattern) (Fig. 6F); to 'Tb' (Fig. $6 \mathrm{~A}$ ) and ' $\mathrm{Ht}$ ' (Fig. 6F) (increasingly prominent tubercles); to 'Tr' (Fig. 6C) and 'Rt' (Fig. 6D) (reticulation with and without tubercles, respectively). The presence of villi represents an additional character state superimposed over pavement or over tubercles (states with villi, Pv and Tv, respectively) (Fig. $6 \mathrm{E})$. For sessoblasts, we examined the microsculpture on the capsule, which is regarded as homologous to the fenestra of the floatoblast. We recorded five states (Tb, Rt, Sm, $\mathrm{Tv}$, and $\mathrm{Ht}$ ). 


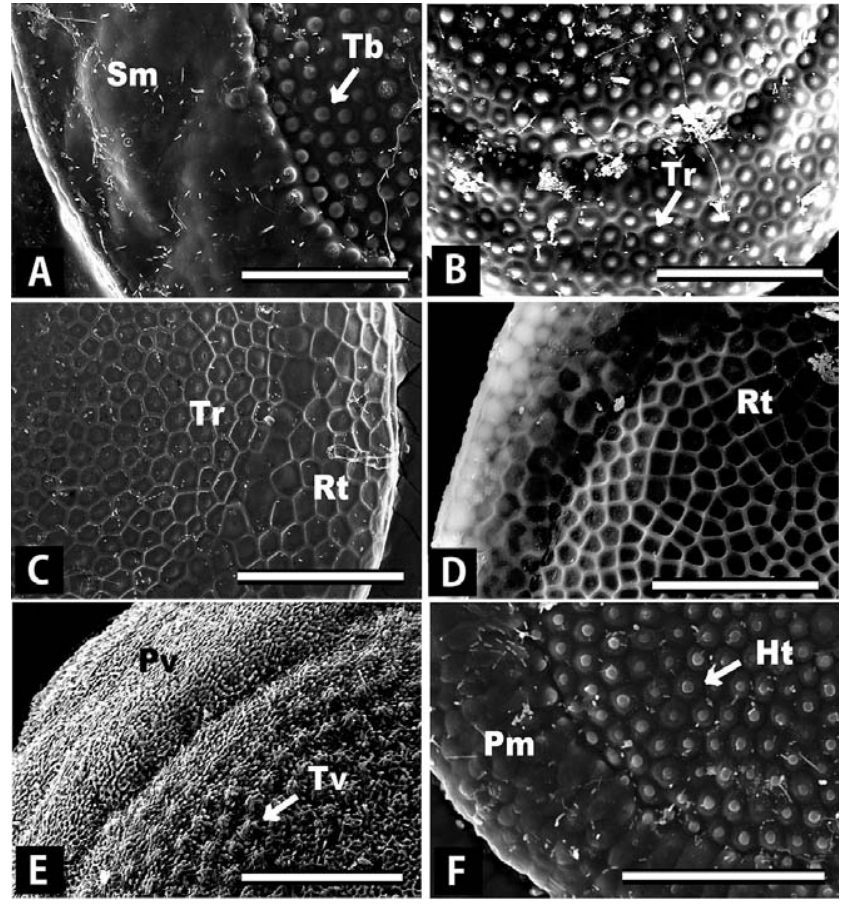

Fig. 6. SEM photomicrographs showing types of microsculpture on the fenestra and annulus of plumatellid floatoblasts. (A) Plumatella repens, dorsal valve. (B) Plumatella fungosa, dorsal valve. (C) Plumatella rugosa, ventral valve. (D) Plumatella vaihiriae, ventral valve. (E) Gelatinella toanensis, ventral valve. (F) Plumatella sp. 2, dorsal valve. Abbreviations: $\mathrm{Ht}$, hypertubercles; Pm, pavement; $\mathrm{Pv}$, pavement with villi; Rt, reticulation; Sm, smooth; Tb, tubercles; $\mathrm{Tr}$, tubercles with reticulation; Tv, tubercles with villi. Scale bars, $50 \mu \mathrm{m}$.

Floatoblast microsculpture is illustrated in Fig. 6 and summarized in the FMs and AMs columns in Table 3. The most common pattern was a tuberculate ( $\mathrm{Tb}$ or $\mathrm{Ht}$ ) fenestra and a pavement-type (Pm) annulus. All taxa except members of the $P$. repens clade showed this pattern; $P$. mukaii and $G$. toanensis were exceptional in having the Tb-Pm pattern overlain by villi (the Tv-Pv pattern). All of the species in Clade 1 had fenestral hypertubercles. Reticulation was observed only in the $P$. repens clade, with three members having both reticulation and tubercles on fenestra and annulus (Tr-Tr, Tr-Rt, Rt-Rt). The monophyly and internal structure of this clade were well supported (Fig. 3), yet curiously the floatoblast of $P$. repens lacked reticulation on the annulus. In most cases, plumatellids showed different character states between fenestra and annulus; only $P$. fungosa and $P$. vaihiriae showed the same states ( $\mathrm{Tr}-\mathrm{Tr}$ and Rt-Rt, respectively); however, in all cases where the microsculpture of the fenestra included villi or reticulation, so did that of the annulus.

Two species in Clade 2 (G. toanensis and $P$. mukaii) had villi on the fenestra and annulus. None of the trees showed these to be sister taxa; villi either originated twice independently (Figs. 2, 3A), or once with a subsequent loss in $P$. reticulata (Fig. 3B). In either case, this character is not phylogenetically informative.

\section{Sessoblast microsculpture}

A summary of sessoblast microsculpture is given in the
'Ses' column of Table 3. In some of the species examined that have sessoblasts, the microsculpture on the sessoblast fenestra (Ses) matched that on the floatoblast fenestra (FMs) (three of 11 species: $P$. vaihiriae, $P$. mukaii, and $P$. emarginata). Two species ( $P$. casmiana and $P$. reticulata) showed a marked difference between sessoblast and floatoblast. In the remaining six species, the sculpture on the floatoblast and sessoblast had an element of tuberculation in common: respectively Tr-Tb in $P$. fungosa, $P$. repens, and $P$. rugosa, $\mathrm{Tv}$ - $\mathrm{Tb}$ in $\mathrm{G}$. toanensis, $\mathrm{Ht}-\mathrm{Tb}$ in $P$. vorstmani, and $\mathrm{Ht}-\mathrm{Tb}$ in Plumatella sp. 1. Interestingly, although reticulation was observed on floatoblasts only in the $P$. repens clade, $P$. reticulata showed reticulation on the sessoblast (but not on the floatoblast); this appears to have been an independent origin of statoblast reticulation.

\section{DISCUSSION}

The re-analyses including cytb sequences (Fig. 3) yielded different backbone topologies from what we obtained in the previous analyses based on $12 S$ and $16 S$ alone (Fig. 2) for the six Clade-2 species (Clades 1 and 2 are indicated in Fig. 2) other than the $P$. repens clade. These differences in topology between analyses of the two data sets may partly reflect differences in taxon sampling; the tree in Fig. 2 was part of a broader phylactolaemate phylogeny, whereas the trees in Fig. 3 included a limited subset of taxa. However, because the backbone topology for Clade 2 received little support in any of the analyses (Figs. 2, 3), the instability in topology was more likely due to insufficient phylogenetic signal.

While individual measurements related to gross floatoblast morphology showed nearly continuous variation, and in many cases similar values among different clades identified in the trees, metric characters in combination discriminated among members of three relatively well-supported clades. This result suggests that there is a phylogenetic component to gross floatoblast morphology-that aspects of floatoblast morphology were transmitted from the common ancestor to its descendents within clades.

A weakness in the study was that we treated only 10 floatoblasts from a single locality, and sometimes from a single colony, as representative of species-level characters. We chose a sample of 10 because this was roughly the sample we had for some species; some other species were known only from local areas (e.g., Plumatella spp. 1 and 2); and in any case, trying to incorporate the range of variation in broadly distributed species was simply intractable. There is extensive published documentation of intraspecific variation among plumatellid populations in both mean floatoblast measurements and mean measurement ratios. Toriumi (1971) reported for $P$. repens, for example, that among Japanese populations, mean SI values ranged from 335 to $410 \mu \mathrm{m}$ and mean SI/Sw values from 1.29 to 1.34; among European populations, mean SI values ranged from 322 to $368 \mu \mathrm{m}$ and mean $\mathrm{SI} / \mathrm{Sw}$ values from 1.25 to 1.40 ; Toriumi (1970) demonstrated that this variation included temperature-induced ecophenotypic variation.

Using a sampling scheme that incorporated high levels of intraspecific variation would have affected our results in two ways. First, it would have reinforced our general conclusion that floatoblast measurements and measurement ratios 
are generally not phylogenetically informative individually, as it would have led to larger dispersions around means that would have nonetheless remained more or less continuously distributed. Second, it would have increased the scatter of points (Fig. 5) in the three clades examined in the discriminant analysis. The analysis would likely still have discriminated the three groups, however, since the groups were well separated even though they encompassed interspecific variation among the two or four species included in each group.

Due to lack of support for the basal nodes in Clade 2 (Fig. 2) and nodes involving the corresponding taxa in Fig. 3 , reconstruction of ancestral character states at best provides hypotheses to be tested in the future with additional data; the following discussion is based on inferences of ancestral states through the method of maximum parsimony (Cunningham et al., 1998) under the assumption that the trees roughly reflect the true topology. The basic element of microsculpture in plumatellids is tuberculation, which ranges from smooth (in which there are traces of tuberculation) (Sm, Fig. 6A), to pavement (Pm, Fig. 6F), to tuberculate (Tb, Fig. 6A), to hypertuberculate (Ht, Fig. 6F). Members of Clade 2 outside the $P$. repens clade show a tuberculate $(\mathrm{Tb})$ fenestra and pavement-type (Pm) annulus, although $P$. mukaii and $G$. toanensis have villi superimposed over this pattern (Tv-Pv). Likewise, members of Clade 1 all have hypertubercles $(\mathrm{Ht})$ on the fenestra and a pavement-type $(\mathrm{Pm})$ annulus. This phylogenetic distribution of character states suggests that the ancestral plumatellid floatoblast had a tuberculate or hypertuberculate fenestra and pavementtype annulus.

Either of two additional patterns, villi or reticulation, can be superimposed on the pattern of tuberculation. Floatoblasts with reticulation were observed only in the $P$. repens clade. This clade was identical in topology in all analyses, and the phylogenetic distribution of character states suggests that the floatoblast in the common ancestor of the $P$. repens clade had both an annulus and fenestra showing reticulation ( $\mathrm{Rt}$ or $\mathrm{Tr}$ ).

The most basal members (G. toanensis, $H$. punctata, $P$. emarginata) in Clade 2 (Fig. 2), some of which are also basal in Fig. $3 A$ and $B$, as well as the basal member in Clade 1 (Plumatella sp. 1) (Fig. 2), showed an asymmetrical floatoblast, with a relatively flat dorsal annulus, suggesting that floatoblast asymmetry was the primitive state in plumatellids. If this is the case, then relatively symmetrical floatoblasts (convex annulus of the dorsal valve) arose independently at least once in each of Clades 1 and 2. An increase in the thickness of the dorsal valve probably results from an increase in the size or number of gas-filled chambers in the dorsal annulus, leading to increased buoyancy, and this has ecological significance. Some species, including $H$. punctata, that have asymmetrical floatoblasts do not become buoyant until after a period of desiccation (Wood and Okamura, 2005). In addition, a thickened valve may enable the floatoblast to survive digestion in the digestive tract of waterfowl, which can serve as vectors for the dispersal of freshwater invertebrates, including bryozoans (Charalambidou et al., 2003; Figuerola et al., 2005; Green et al., 2008); increasing the floatoblast survival rate would increase the chance of dispersal.

Like others before (Toriumi, 1956) and after (Mukai,
1999) him, Lacourt (1968) considered Fredericella as the basal group among phylactolaemates, under the assumption that 'small' and 'simple' were primitive. That is, he considered Fredericella basal because the colony comprises sparsely branched tubes, with low zooid density; zooids are relatively small, with few tentacles; and the only type of statoblast is a small sessoblast (piptoblast). Lacourt (1968) grouped species into several evolutionary series, derived from Fredericella or from intermediate links to Fredericella, based on increasing colony integration and zooid density; increasing zooid size and tentacle number; addition of a floatoblast to the life history; and increasing size and complexity of statoblasts. Recent molecular phylogenies (Wood and Lore 2005; Okuyama et al., 2006; Hirose et al., 2008) have inverted Lacourt's phylogeny, showing fredericellids and plumatellids to be sister groups, and derived rather than basal. The reason for this discordance is clear: the original assumption that 'small' and 'simple' indicate the primitive condition was erroneous.

Despite the discordance, molecular studies have corroborated at least one aspect of Lacourt's (1968) phylogeny: a close relationship between Plumatella repens and $P$. fungosa. In addition to this relationship based on a "short oval statoblast", Lacourt (1968) postulated two other species groups ('evolutionary series') in Plumatellidae, one comprising species with an "elongated oval statoblast" ( $P$. philippinenensis, $P$. agilis, $P$. carvalhoi, $P$. fruticosa) and the other comprising species with a "medium oval statoblast" $(P$. javanica, $P$. longigemmis, $P$. emarginata, $P$. [Gelatinella] toanensis). For these latter two species groups, our study included only $P$. emarginata and $G$. toanensis, and we thus cannot judge the validity of the groups. However, an examination of the $P$. repens group is informative. Lacourt (1968) placed $P$. vaihiriae distant from the $P$. repens group due to the elongation in this species of the floatoblast annulus at the poles. Lacourt (1968) considered $P$. vaihiriae to be relatively basal due to its low tentacle number, and to represent a link between Plumatellidae and Lophopodidae, because the immature floatoblast in species of Lophopus and Lophopodella resembles that of $P$. vaihiriae. In contrast, our trees (Fig. 3 ) include $P$. vaihiriae in the $P$. repens group, with high nodal support.

Our results explain this discordance: individual metric or proportional characters of gross statoblast morphology are generally not phylogenetically informative, although in combination they can discriminate between clades. Likewise, characters of statoblast microsculpture are not generally phylogenetically informative. Although some character states are restricted to certain clades, not all members of the clades show the states; in some cases, character states are clearly convergent. Overall, our results suggest that statoblast morphology is not very phylogenetically constrained, but appears to be highly susceptible to selection. Finally, we note that regardless of their utility in reconstructing phylogeny, statoblasts are still useful for species discrimination.

\section{ACKNOWLEDGMENTS}

We thank Tim Wood (Wright State University, USA) for providing specimens from North America and Thailand, and Samantha Hill (University of Reading, UK) for specimens from Britain. This study was partly supported by the 21 st Century COE Program "Neo- 
Science of Natural History" at Hokkaido University, funded by the Ministry of Education, Culture, Sports, Science and Technology (MEXT), Japan.

\section{REFERENCES}

Charalambidou I, Santamaria L, Figuerola J (2003) How far can the freshwater bryozoan Cristatella mucedo disperse in duck guts? Arch Hydrobiol 157: 547-554

Cunningham CW, Omland KE, Oakley TH (1998) Reconstructing ancestral character states: a critical reappraisal. Trends Ecol Evol 13: 361-366

Figuerola J, Green AJ, Michot TC (2005) Invertebrate eggs can fly: evidence of waterfowl-mediated gene flow in aquatic invertebrates. Am Nat 165: 274-280

Geimer G, Massard J (1986) Les bryozoaires du Grand-Duche de Luxembourg et des regions limitrophes. Transv Sci Mus Hist Nat Luxembourg 7: 1-187

Green AJ, Jenkins KM, Bell D, Morris PJ, Kingsford RT (2008) The potential role of waterbirds in dispersing invertebrates and plants in arid Australia. Freshwater Biol 53: 380-392

Hirose M, Dick MH, Mawatari SF (2008) Molecular phylogenetic analysis of phylactolaemate bryozoans based on mitochondrial gene sequences. In "Bryozoan Studies 2007" Ed by SJ Hageman, MM Key Jr, JE Winston, Special Publication Number 15, Virginia Museum of Natural History, Martinsville, VA, pp 6574

Kraepelin K (1887) Die deutschen Susswasser-Bryozoen. Monogr Abh Naturwiss Hamburg 10: 1-168

Lacourt AW (1968) A monograph of the fresh-water BryozoaPhylactolaemata. Zool Verh Utigeg Rijksmus Natl Hist Leiden 93: 1-159

Massard JA, Geimer G (2008) Global diversity of bryozoans (Bryozoa or Ectoprocta) in freshwater. Hydrobiologia 595: 93-99

Merritt TJS, Shi L, Chase MC, Rex MA, Etter RJ, Quattro JM (1998) Universal cytochrome $b$ primers facilitate intraspecific studies in molluscan taxa. Mol Mar Biol Biotechnol 7: 7-11

Mukai H (1999) Comparative morphological studies on the statoblasts of lower phylactolaemate bryozoans, with discussion on the systematics of the Phylactolaemata. Sci Rep Fac Educ Gunma Univ 46: 51-91

Nylander JA (2004) MrModeltest 2.2. Evolutionary Biology Center, Uppsala University http://www.ebc.uu.se/systzoo/staff/nylander. html

Okuyama M, Wada $H$, Ishii T (2006) Phylogenetic relationships of freshwater bryozoans (Ectoprocta, Phylactolaemata) inferred from mitochondrial ribosomal DNA sequences. Zool Scr 35: 243-249

Posada D, Crandall KA (1998) Modeltest: testing the model of DNA substitution. Bioinformatics 14: 817-818

R Development Core Team (2008) R: a language and environment for statistical computing. R Foundation for Statistical Computing, Vienna, Austria http://www.R-project.org

Tamura K, Dudley J, Nei M, Kumar S (2007) MEGA4: Molecular Evolutionary Genetics Analysis (MEGA) Software, Version 4.0. Mol Biol Evol 24: 1596-1599

Thompson JD, Higgins DG, Gibson TJ (1994) CLUSTAL W: improving the sensitivity of progressive multiple sequence alignment through sequence weighting, position specific gap penalties and weight matrix choice. Nucleic Acids Res 22: 4673-4680

Toriumi M (1956) Taxonomical study on fresh-water Bryozoa. 17. General consideration: interspecific relation of described species and phylogenic consideration. Sci Rep Tohoku Imp Univ (Ser 4) 22: 57-88

Toriumi M (1970) Additional observations on Plumatella repens (L.) (a fresh-water bryozoan) III. Variation of the floatoblasts at low temperature. Bull Mar Biol Stn Asamushi 14: 27-32

Toriumi M (1971) Additional observations on Plumatella repens (L.) (a fresh-water bryozoan) IV. Re-examination on the field materials of $P$. repens and $P$. fungosa. Bull Mar Biol Stn Asamushi 14: 117-125, pls 8-10

Wiebach F (1975) Specific structures of sessoblasts (Bryozoa Phylactolaemata). Docum Lab Géol Lyon HS 3: 149-155

Wood TS (1988) Plumatella reticulata sp. nov. in Ohio (Bryozoa: Phylactolaemata). Ohio J Sci 88: 101-104

Wood TS (1989) Ectoproct bryozoans of Ohio. Ohio Biol Surv Bull N S 8(2): i-x, 1-70

Wood TS (1998) Reappraisal of Australian freshwater bryozoans with two new species of Plumatella (Ectoprocta; Phylactolaemata). Invertebr Taxon 12: 257-272

Wood TS (2001a) Plumatella mukaii, a new phylactolaemate bryozoan from Asia and South America. Hydrobiologia 445: 51-56

Wood TS (2001b) Three new species of plumatellid bryozoans (Ectoprocta: Phylactolaemata) defined by statoblast nodules. J N Am Benthol Soc 20: 133-143

Wood TS, Lore MB (2005) The higher phylogeny of phylactolaemate bryozoans inferred from $18 \mathrm{~S}$ ribosomal DNA sequences. In "Bryozoan Studies 2004" Ed by I Hugo, G Moyano, JM Cancino, PN Wyse Jackson, Taylor \& Francis, London, pp 361367

Wood TS, Okamura B (2005) A new key to the freshwater bryozoans of Britain, Ireland and continental Europe, with notes on their ecology. Freshwater Biological Association, Cumbria, UK

Wood TS, Wood LJ, Geimer G, Massard, J (1998) Freshwater bryozoans of New Zealand: a preliminary survey. NZ J Mar Freshwater Res 32: 639-648

Wood TS, Anurakpongsatorn P, Mahujchariyawong J (2006) Freshwater bryozoans of Thailand (Ectoprocta and Entoprocta). Nat Hist J Chulalongkorn Univ 6: 81-117

(Received June 30, 2010 / Accepted November 6, 2010) 